\title{
Results of the Helsinki magnetic observatory 1844-1912
}

\author{
H. Nevanlinna \\ Finnish Meteorological Institute, Geophysical Research Division, P.O.Box 503, FIN-00101 Helsinki, Finland \\ Received: 14 August 2003 - Revised: 20 October 2003 - Accepted: 20 November 2003 - Published: 8 April 2004
}

\begin{abstract}
The geomagnetic field declination $(D)$ and horizontal component $(H)$ were observed visually at the Helsinki magnetic observatory between 1844-1912. About 2.0 million single observations of the magnetic components are available. The observing equipment and observation methods were the same for almost 70 years. The Helsinki data series is thus rather homogeneous and suitable for magnetic field analysis of both internal and external origin for about five sunspot cycles (sunspot cycles 9-13). Due to disturbances from nearby electric tramway traffic, most of the observations after 1897 are very noisy and unreliable for magnetic activity studies. Observations of $D(1844-1897)$ have been converted into an absolute scale but $H$ refers to variation values only. Observations of $D$ have been previously analyzed and published for the time interval 1844-1880. In this paper we present new results of $D$ for 1881-1897 and $H$ for $1844-1897$. The annual rate of the secular variation of $D$ has been rather stable between 1844-1909, showing a mean eastward increase of $+0.11^{\circ}$ year, which is about twice as large as the mean secular variation rate for the past 50 years at the same latitude in Finland. Around 1875 there was a sudden change in the secular variation rate resembling the famous jerk of 1970 . Magnetic activity indices $(K, A k)$ for 1844-1897 were calculated from hourly values of $D$ and $H$-series separately using the IAGA $K$-index algorithm (the FMI-method). Comparisons with other relevant activity series from other sources ( $a a, u, R I, C 9$, auroral occurrence rate) show that the Helsinki index series gives an important contribution to the index family. By extending the Mayaud's $a a$-index series with Helsinki $A k$-values (18441868), it is possible to reconstruct a (pseudo) $a a$-series that covers almost 160 years. Magnetic activity (space weather) was appreciably greater during the first three cycles (9-11) than during the two last ones (12-13). The largest magnetic storm occurred in September 1859. Other stormy periods were in 1847,1852 , and 1870-1872. Mean magnetic activity remained exceptionally low in years 1875-1881 and 18871891. In an $F F T$-analysis of the activity index series, the solar cycle, annual, semiannual, solar rotation and half solar rotation spectral lines are well established.
\end{abstract}

Correspondence to: $\mathrm{H}$. Nevanlinna

(heikki.nevanlinna@fmi.fi)
Key words. Geomagnetism and paleomagnetism (time variations, diurnal to secular) - History of geophysics (planetology) - Magnetospheric physics (solar wind-magnetosphere interactions)

\section{Introduction}

Geomagnetic phenomena, occurring both in time and space, were intensively studied already at the turn of the 18th and 19 th centuries. The theoretical study of geomagnetism in the 1820s received an enormous momentum from the discovery of the electromagnetic interaction demonstrated by $\mathrm{H}$. C. Oersted and later by other famous physicists like Faraday and Ampere. The accuracy of geomagnetic observatory instruments was greatly increased through the invention of the suspended magnet (or torsion balance) by Coulomb and Cassini in Paris in the 1790s (e.g. McConnell, 1980; Multhauf and Good, 1987). Poggendorf's variometer, based on the mirror-and-scale method (e.g. Chapman and Bartels, 1940), enhanced the sensitivity of magnetic recordings compared with magnetometers used, for example, earlier in the 18th century by G. Graham and A. Celsius (e.g. McConnell, 1980; Beckman, 1999; Stern, 2002).

The leading figure in the geomagnetic community in the early 19 th century was A. von Humboldt. Mainly by his influence geomagnetic observatories were set up in many countries like Great Britain and its overseas territories, France, Germany and Russia (e.g. Good, 1988; Malin and Barraclough, 1991; Schröder and Wiederkehr, 2001). In continental Europe an international geomagnetic observatory cooperation was organized by "The Magnetic Union" (founded in 1836) in Göttingen, directed by Gauss and Weber (Chapman and Bartels, 1940). Great Britain and France fulfilled large-scale scientific expeditions to gather geomagnetic and other geophysical data on a worldwide scale. The "Magnetic Crusade", organized by Sir Edward Sabine, was one example of the extensive geomagnetic research projects of the 19th century (Cawood, 1977, 1979).

In a very short time in the 1840 s some 20 geomagnetic observatories were set up around the world. Magnetic observations were made according to the procedures developed 

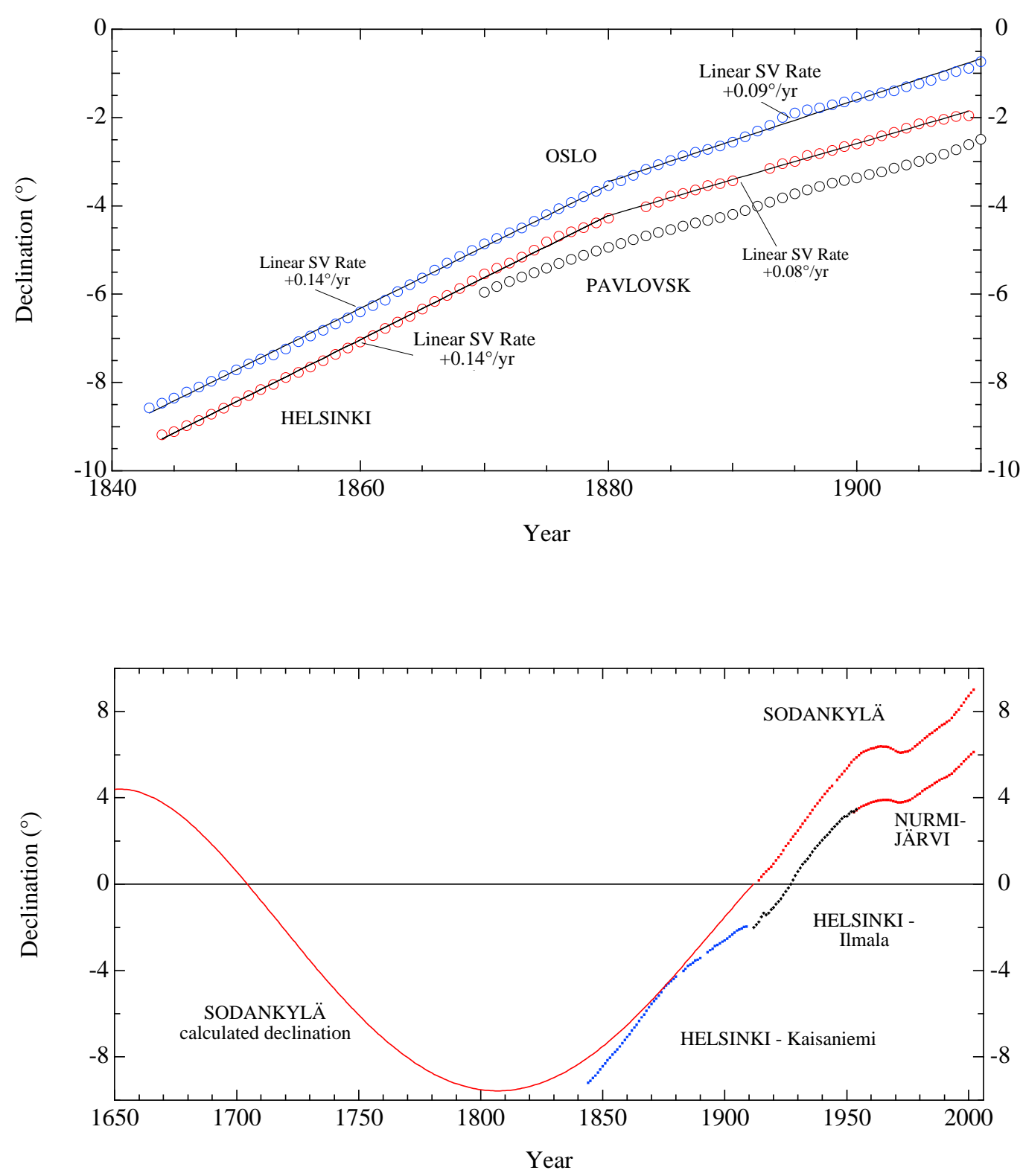

Fig. 1. Upper panel: Annual means (circles) of declination from the Helsinki, Oslo (offsetted by $10^{\circ}$ ) and Pavlovsk observatories. The secular variation $(S V)$ of $D$ has been stable over 70 years during the 19th century. The linear $S V$ rate was rather abruptly changed in the 1870s in connection with a geomagnetic jerk (Alexandrescu et al., 1997). Lower panel: Long series of the declination in Finland. The observatory series are Helsinki (Kaisaniemi), 1844-1908 and its successors Helsinki (Ilmala), 1908-1953, and Nurmijärvi (1953-). The Sodankylä magnetic observatory series started in 1914. The solid line before 1914, continuing to the year 1650, is a polynomial $(\phi, \lambda, t)$ of declination calculated with the coordinates of Sodankylä $\left(\phi=67^{\circ} 22^{\prime} \mathrm{N} ; \lambda=26^{\circ} 38^{\prime} \mathrm{E}\right)$. The polynomial is a fit of all magnetic survey $(D)$ data in Finland, 1600-1950 (Nevanlinna, 1979).

by Gauss (Chapman and Bartels, 1940). In Finland the first magnetic observatory was founded in 1838 by the initiative of A. Kupffer (1799-1865), the director of the Russian magnetic observatories (Simojoki, 1978; Holmberg, 1992). The observatory was set up in the park of Kaisaniemi, which is in the very centre of present day Helsinki. Finland was a part of the Russian empire at that time, but the observatory remained organisationally under the University of Helsinki and was funded by the Finnish government. The first direc- tor of the Helsinki observatory was Professor of Physics J. J. Nervander (1805-1848), who was a very active and skilful geomagnetician. His design was one of the earliest versions of a galvanometer (tangent bussole; Nervander, 1833). Under Nervander's leadership the new observatory was equipped with the best variometers and other geomagnetic instruments developed in Göttingen by “The Magnetic Union”.

Regular magnetic and meteorological observations started on 1 July 1844. There were 12 assistants making 


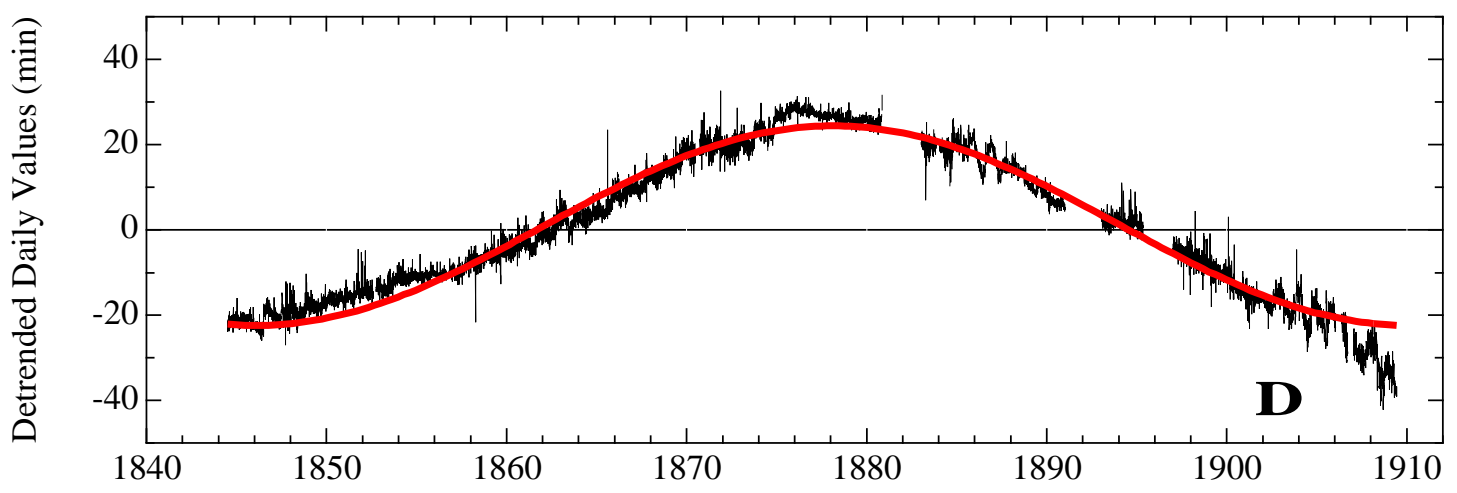

Year

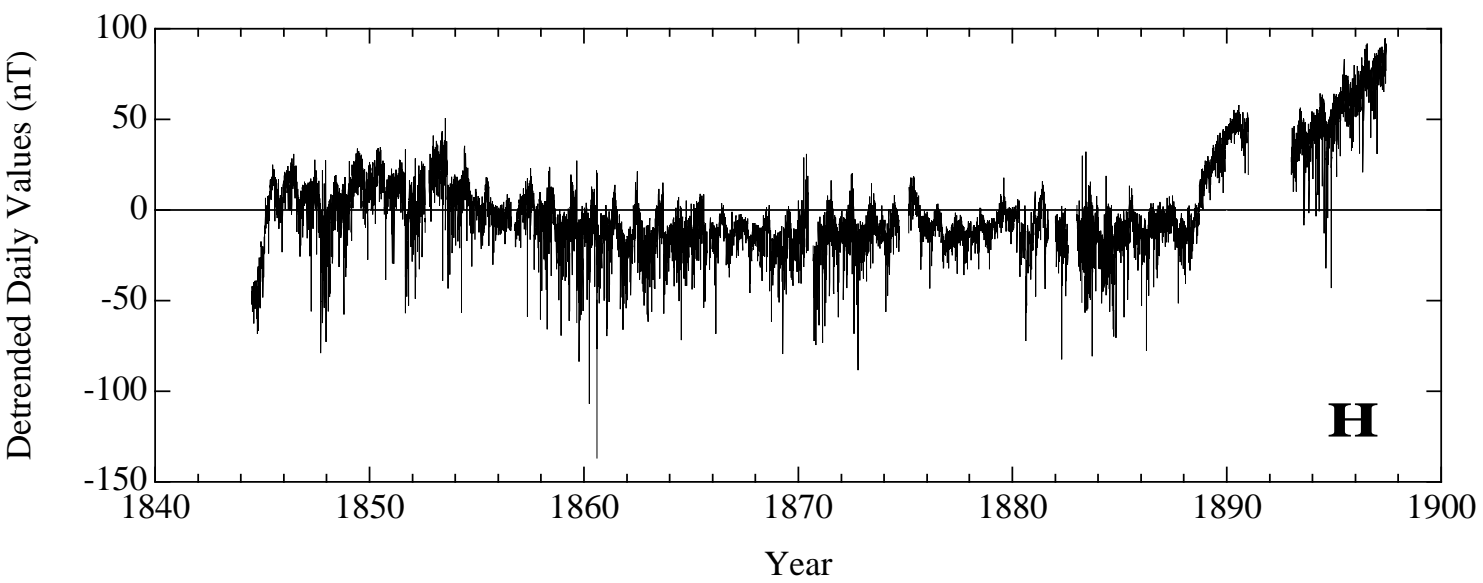

Fig. 2. Daily residuals of $D$ (upper panel) and $H$ (lower panel) after removal of the long-term trend. The observed values of $H$ were not absolute and thus their long-term trend (an exponential decay) does not represent any true secular variation but rather slow changes in the variometer instrument itself. In $\Delta D$, the long-term linear trend (see Fig. 1) is a signature of the real secular variation. A smoothly varying quasi-sinusoidal secular variation component (see, Eq. 1) is shown by the red curve. $\Delta D$ is converted to nT-unit by multiplying it by 4.4 .

observations every $10 \mathrm{~min}$, later (1857-1897) hourly. The magnetic elements observed were the declination $(D)$, the horizontal $(H)$ and vertical $(Z)$ components (for more details, see Nevanlinna, 1997).

The observation results (1844-1848) under Nervander's directorship were published in magnetic yearbooks (Nervander, 1850). After the death of Nervander the observatory routines continued almost unchanged for more than 60 years. The observation method of the variometers and the site of the instruments remained the same until 1912, when the observatory was closed due to magnetic disturbances caused by the nearby electric tramway. Magnetic observations started again in 1912 in the new meteorological observatory (Ilmala) some $20 \mathrm{~km}$ north of the Helsinki (Kaisaniemi) observatory. Later, a new geomagnetic observatory was set up in Nurmijärvi (1952), about $40 \mathrm{~km}$ north of Helsinki (see Fig. 1).

After Nervander's death observations were not published but the original hand-written results have been saved. During the 1990s, all usable geomagnetic observation data, about 2.0 million single observations, were converted to electronic form. Of the two components $(H$ and $D)$, the declination data (1844-1909) and magnetic activity indices derived from it (1844-1897) were published by Nevanlinna et al. (1992a, b, 1993) and Nevanlinna and Ketola (1993, 1994).

In this paper we present results about the secular variation of the geomagnetic field, as well as about magnetic activity based on the analysis of the Helsinki magnetic data collected during 1844-1909. Observations of $D$ have been previously analyzed and published for the time interval 1844-1880. In this paper we present new results of $D$ for 1881-1897 and $H$ for 1844-1897. In addition, some examples of other digitized magnetic results from the 19th century's observatories are given.

\section{Compilation of geomagnetic data}

At the Helsinki geomagnetic observatory $\left(\phi=60^{\circ} 10^{\prime} \mathrm{N}\right.$; $\left.\lambda=24^{\circ} 57^{\prime} \mathrm{E}\right)$ three components of the magnetic vector were observed: declination $(D)$, horizontal field $(H)$, and vertical field $(Z)$ intensity. Observations were visual spot readings of the magnet position aided by a telescope (for more details, 
see Nevanlinna, 1997). $D$ - and $H$-observations were made 6 times per hour. $Z$ was observed 3 times in an hour. These observations were carried out almost constantly without interruption for 14 years between 1844-1857. After that observations continued hourly for the subsequent 40 years until 1897. The quality of the observations deteriorated greatly when the electric tramway traffic started in the vicinity of the observatory in 1901. Observations were stopped in 1912. During the last years, observations were made only three times per day. During the 67 years, when the observatory was operating, about 2.0 million single observations $(D, H$ and $Z$ ) of magnetic field values were made. Not much of these data were processed in the 19th century but the original records have survived. Observations of $D$ at the Helsinki observatory have recently been processed and the quality of the data has been revealed to be high (see, e.g. Nevanlinna and Kataja, 1993; Nevanlinna, 1995).

The quality of the $Z$-measurements is poor due to the unstable magnetometer (Lloyd's magnetic balance) baseline and the $Z$-values cannot be used in data analyses. $H$ - and $D$ measurements are of good quality and the instrument constants are known. However, only $D$-measurements can be utilized for studies of secular variation, because $H$-values are variation data, as their absolute values are not known.

Figure 1 shows daily values of the declination $(\Delta D)$ and of the horizontal component $(\Delta H)$ after removing long-term trends. In the case of declination the linear trend represents a true secular variation, whereas in the horizontal component the trend (exponential decay) is caused by changes in the variometer itself. One can see in Fig. 2, that the homogeneity of the data is good, especially before 1880 , in both components. There are several gaps in the data, which are mostly due to lost observation data.

\section{Secular variation of $D$}

Figure 1 depicts the annual means of declination in Helsinki in 1844-1909. The annual means from Oslo $\left(\phi=59^{\circ} 55^{\prime} \mathrm{N}\right.$; $\left.\lambda=10^{\circ} 43^{\prime} \mathrm{E}\right)$ and Pavlovsk $\left(\phi=59^{\circ} 41^{\prime} \mathrm{N} ; \lambda=30^{\circ} 29^{\prime} \mathrm{E}\right)$ are shown for comparison. Oslo is located some $700 \mathrm{~km}$ to the west, and Pavlovsk about $300 \mathrm{~km}$ east of Helsinki. The secular variation $(S V)$ at all three observatories has been almost linear for decades, in contrast to the $S V$ in the 20th century, during which five great jerks occurred in $D$. In the 1870 s the linear $S V$ rate changed rapidly in connection to the geomagnetic jerk of 1870 (Alexandrescu et al., 1995, 1996, 1997). The $S V$ rate was higher $\left(0.14^{\circ} /\right.$ year) in Helsinki during $1840-1870$ than during the latter part $\left(0.08^{\circ} /\right.$ year $)$, which is more than $50 \%$ higher than the $S V$ rate at the Nurmijärvi observatory (the present day successor of the Helsinki observatory during the last 50 years). The $S V$ in Helsinki can be approximated by a linear part, plus a simple sinusoidal variation as follows:

$$
D(t)=-5.1^{\circ}+0.112^{\circ} t+0.4^{\circ} \sin \left(360^{\circ} t / 64+71^{\circ}\right)
$$

where $t=y e a r-1875$. The sinusoidal part can be interpreted as a signal of the 60-year variation of the geomagnetic field similar to that found in the $S V$ in the 20th century (e.g. Yukoyama and Yukutake, 1991). Figure 2 (upper panel) shows the detrended (linear part) daily variations of the declination $(\lambda D)$ between 1844-1909 maintaining the 60-year variation. Thus, the sinusoidal character of the Helsinki D 1844-1909 gives additional support to the 60-year phenomenon.

The first successor of the Helsinki (Kaisaniemi) magnetic observatory was the Helsinki (Ilmala) meteorological observatory, located some $20 \mathrm{~km}$ north of Helsinki (Kaisaniemi), where magnetic observations (declination only) started in 1912 and they stopped in 1953. The Nurmijärvi magnetic observatory (1953-) continues today with the magnetic observation programme of the Kaisaniemi and Ilmala observatories. Figure 1 (lower panel, dots and crosses) shows the annual means of the declination in Finland as determined from these three observatories since 1844. In addition, there is the declination series from the Sodankylä observatory that has been in operation since 1914. The solid line in Fig. 1 (lower panel) represents the probable time variation of the declination at Sodankylä. It is a polynomial $(\phi, \lambda, t)$ fit to all geomagnetic survey data $(D)$ carried out in Finland since 1600 (Nevanlinna, 1979). Figure 1 (lower panel) illustrates the 350-year long declination series in Finland, where survey and observatory data are combined.

\section{Geomagnetic activity index series}

In a broad sense the geomagnetic activity includes all kinds of transient variations in the magnetic field caused by sources outside the Earth, in contrast to the slow secular variation born in the Earth's core. In a narrower sense the geomagnetic activity is related to residual irregular magnetic changes extracted from the smoothly varying field, such as the regular daily variation. So defined, the magnetic activity correlates with solar activity, which manifests itself by energy and particle outbursts, for example, solar flares and coronal mass ejections added to the continuous solar wind plasma.

Usually magnetic activity is described by a series of discrete index numbers characterizing local or global variations of the magnetic field within time intervals longer than the sampling interval of the original observations. Geomagnetic indices give summarized proxy information about complicated solar activity phenomena and their periodical signatures in the magnetosphere (e.g. Delouis and Mayaud, 1975; Vennerström and Friis-Christensen, 1996; Kane, 1997). Long-term index series are important proxy tools when studying long-term changes in the solar activity and space climate in the near-Earth space environment.

The most commonly used activity index is Bartels' $K$ index (Chapman and Bartels, 1940; Menvielle and Berthelier, 1991), which provides a homogeneous sequence of three-hour values of magnetic effects of magnetospheric electric currents caused by solar wind particles. The 


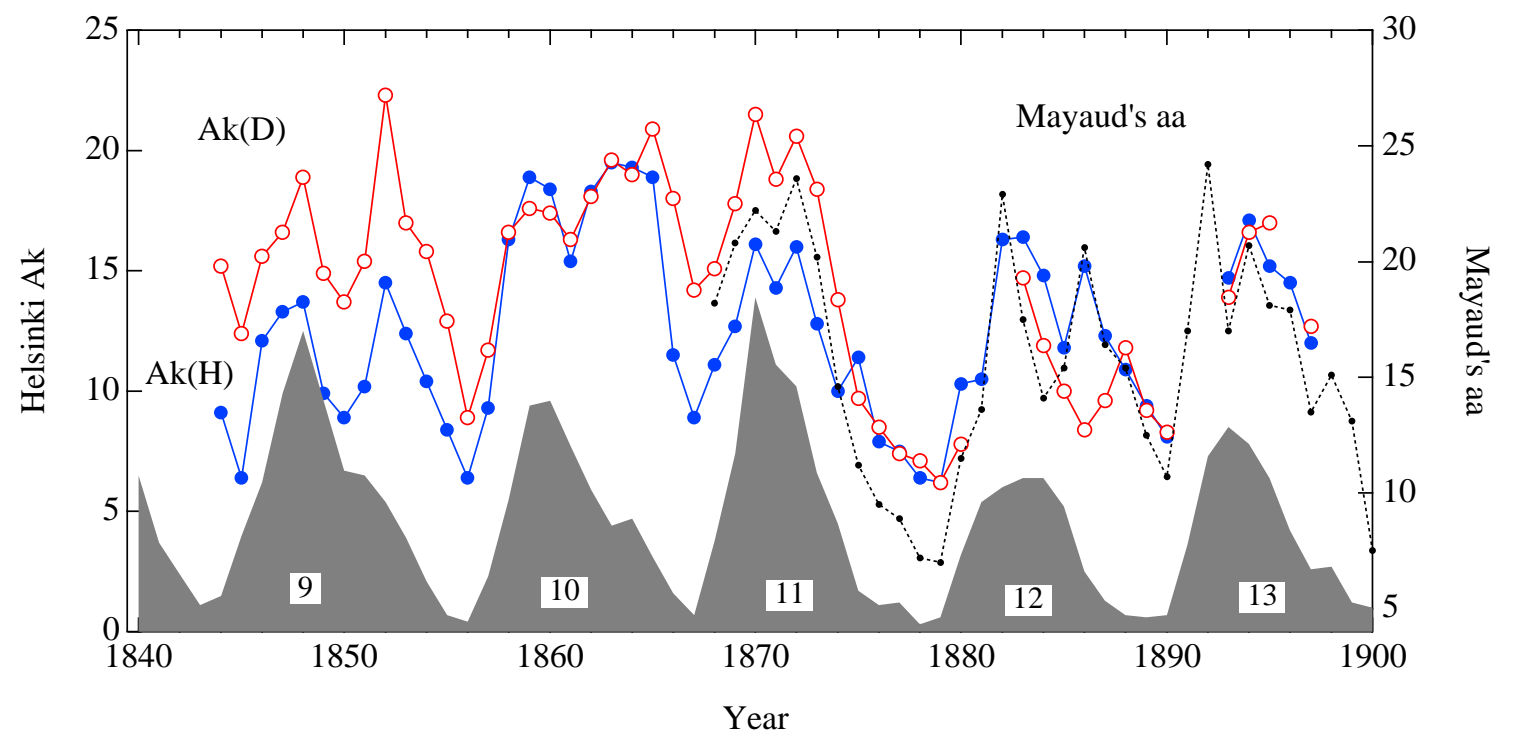

Fig. 3. Annual values of activity indices. $A k(H)$ (blue) and $A k(D)$ (red) are derived from the $H$ - and $D$-components, respectively, using the Helsinki data. The calculation of the activity indices has been carried out by using the FMI-algorithm (Sucksdorff et al., 1991). The black line represents Mayaud's activity index $a a$ (starting in 1868). The dark area at the bottom shows annual means of sunspot numbers. The labels attached with sunspots are numbers of solar cycles.

magnetic activity number $A k$ derived from eight $K$-indices characterizes the daily magnetic activity.

Mayaud's $a a$-index belongs to the $K$-index family (Rangarajan, 1989). It is determined from two hemispherically antipodal observatories in England and Australia, giving perhaps the simplest global index free from local time variations. The importance of the $a a$-series as a proxy tool in solar-terrestrial studies lies in its long duration (since 1868 until present) and in the high degree of homogeneity (Clilverd et al., 2002). Note, however, the criticism introduced by Svalgaard et al. (2003) concerning the secular trend of the $a a$-series in the 20th century, that have been claimed to be erroneous. Recent proofs of the usefulness of the $a a$-index series have been given, for example, by Cliver et al. (1998), Stamper et al. (1999), Lockwood et al. (1999), and Lockwood (2003). They utilized the $a a$-index series in studies of long-term trends in the solar flux and solar irradiance in connection with the Earth's global temperature changes.

The $K$-indices were originally hand-scaled from analogue magnetograms. However, there are several algorithms that are now used for automatic production of the $K$-index from digital magnetic data (e.g. Menvielle et al., 1995). We have applied the FMIK-index method (Sucksdorff et al., 1991) for calculations of the activity index from Helsinki data. The regular daily variation $(S r)$ is removed by fitting a 5 th degree polynomial for each 24-h data series before the $K$-indices were determined from the residual.

Because the Helsinki data consists of discrete readings with a constant time interval, the activity index series must be calibrated to correspond to a continuous magnetic recording. This was done by adjusting the percentage occurrence rate of 3-h $K$-indices in each of 10 bins to be the same as in the corresponding distribution from the present day Nurmijärvi observatory. This was achieved by varying the Helsinki $K=9$ lower limit $(K 9)$. The best correspondence with Nurmijärvi was attained by fixing $K 9=200 \mathrm{nT}$ for both $D$ and $H$ variations. An evidence of the usefulness of the Helsinki activity data was demonstrated by Nevanlinna and Kataja (1993), who showed that the correlation coefficient between the monthly means of the activity index $A k$ (as derived from $D$ ) and the corresponding values of $a a$ for the overlapping time $1868-1880$ is very high, 0.96 . This means that the Helsinki index series can be used as an (quasi) extension of the $a a$-series at least on a monthly to annual time scale. In this way, a geomagnetic activity index series is available, covering almost 160 years since 1844 .

In this study we have used the $D$ - and $H$-series separately for determining the activity index series $(K, A k)$. As the $D$ and $H$-observations have been made by independent magnetometers, the two activity series, $A k(D)$ and $A k(H)$, respectively, provide an internal check of the reliability of the activity data. Figure 3 shows the annual means of $A k(D)$, $A k(H), a a$ and sunspot numbers $(R)$ for 1844-1900. All three geomagnetic activity indices show very similar temporal behaviour but the $A k(H)$ and $A k(D)$ curves seem to be systematically different for several years. The reason for this discrepancy is not known. It may be caused by some longterm changes in the variometers but the source of the systematic differences may also be a consequence of the different time-variation of the $H$ - and $D$-components. It is known that $H$ is greatly depressed during geomagnetic storms but variations in $D$ are not so pronounced.

Both the $A k(D)$ and $A k(H)$ series overlap with the Mayaud's $a a$-index for 30 years since 1868. A linear 

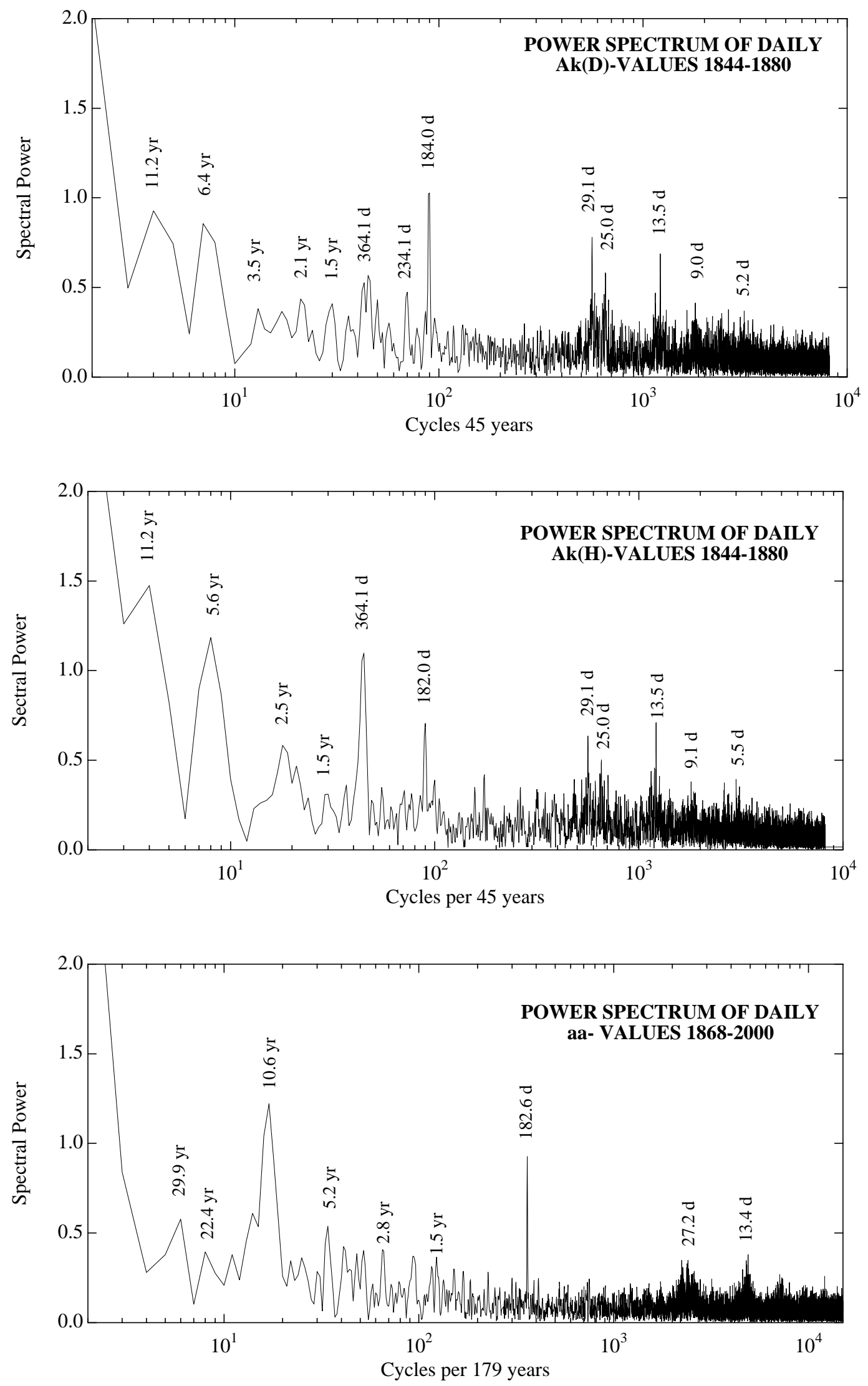

Fig. 4. Power spectra of daily Helsinki activity indices $A k(D)$ (top), $A k(H)$ (middle), and of $a a$ (bottom). 


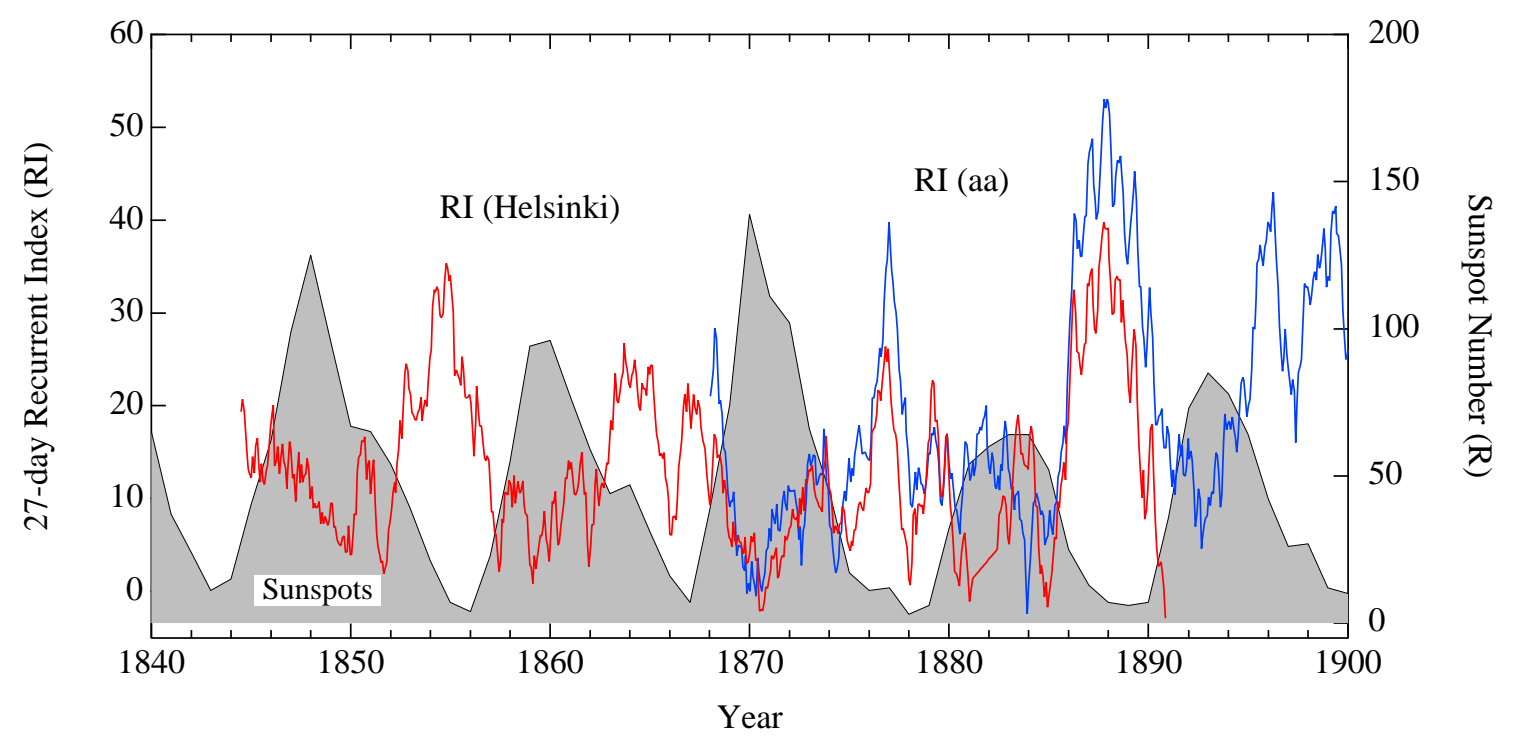

Fig. 5. Sargent's recurrent activity index $(R I)$ calculated from daily values of Helsinki data $(A k(H))$ and Mayaud's $a a$. Sunspot numbers are shown at the bottom.

fit between the annual means (1868-1897) of the $a a$ and Helsinki activity indices $A k(D)$ and $A k(H)$ yields correlation coefficients 0.94 and 0.88 , respectively.

As revealed from the Helsinki activity index series (18441897) there were the following days with severe magnetic conditions (daily $A k>150$ ): 24 September 1847, 20 December 1847, 18 February 1852, 9 April 1858, 3 September 1859, 29 February 1860, 5 August 1865, 17 October 1870, 24 October 1872, from which the September 1859 storm was probably one of the strongest ever experienced (e.g. Fritz, 1873; Silverman, 1995; Boteler et al., 1998; Tsurutani et al., 2003).

The overall level of geomagnetic activity after 1872 until the beginning of the 20th century was much lower than during the decades before it. However, there were some exceptionally great single magnetic storms, like the one on 20 November 1882 (in the First Polar Year), which is still in the top-ten list of big magnetic storms (Helsinki observatory routines were temporarily stopped in autumn 1882).

\subsection{Power spectra}

Figure 4 depicts the power spectra of the activity indices $A k(H), A k(D)$ and $a a$ obtained by using the Fast Fourier Transform $(F F T)$. The $A k(H)$ and $A k(D)$ spectra have been derived using data from 36 years (1844-1880), and for $a a$ from 132 years (1868-1999). The reason to restrict the FFT analysis of the Helsinki data to a 36-year interval, although there exists data until 1895 , is that the homogeneity of the index series is highest in 1844-1880, and there are many more gaps in the data after 1880 than before it. The procedure for the $F F T$-calculations is similar to that used by Fraser-Smith (1972) for the Ap-series, 1930-1972 and Delouis and Mayaud (1975) for $a a$-indices, 1868-1967. Again, there is a good overall similarity in the spectral line distributions. However, there are certain differences. The 132-year $a a$-series (Fig. 4) shows weak signatures of long periodicity of the magnetic activity cycles: the Brückner cycle (29.9/year) and the Hale cycle (22.4), which could not be seen in the $A k(H)$ and $A k(D)$-spectra due to the short time of the data. Approximately the same lines were found by Fraser-Smith (1972) and Delouis and Mayaud (1975) but they were not detected by Clua de Gonzales et al. (1993) from the analysis of the Ap-series 1930-1980. The rather weak 22.4-year line is connected to the double solar-cycle periodicity, as discussed, for example, by Russell and Mulligan (1995) and Cliver et al. (1998).

The period of the solar-cycle in the Helsinki data is 11.2 years, which is half a year longer than the 10.6 years revealed by the $a a$-series. The change in length of the sunspot-cycle seen in the spectral analysis may be due to the fact that the length of the sunspot cycle has shortened rather systematically since the 20th century, as pointed out, for example, by Friis-Christensen and Lassen (1991).

The 11-year peak in activity spectra is usually accompanied by a spectral line with a period of about 5-6 years (Fraser-Smith, 1972; Delouis and Mayaud, 1975; Clua de Gonzales et al., 1993), which also can be seen in the $a a$ - and $A k$-spectra (Fig. 4). In the Helsinki spectra there appear such strong lines at 6.4 years $(D)$ and 5.6 years $(H)$. However, the amplitude of the line is strongly dependent on the activity behaviour during the solar cycles included in the spectrum. In the $a a$-spectrum that covers 132 years, the 5 -year peak is relatively weak. According to, for example, Clua de Gonzales et al. (1993), these lines are signatures of the double (or sometimes triple) peak structure of the geomagnetic activity in the 11-year solar cycle. The double-peak configuration of the annual activity curves is particularly clearly present in cycles 9 and 12, as shown in Fig. 3. 


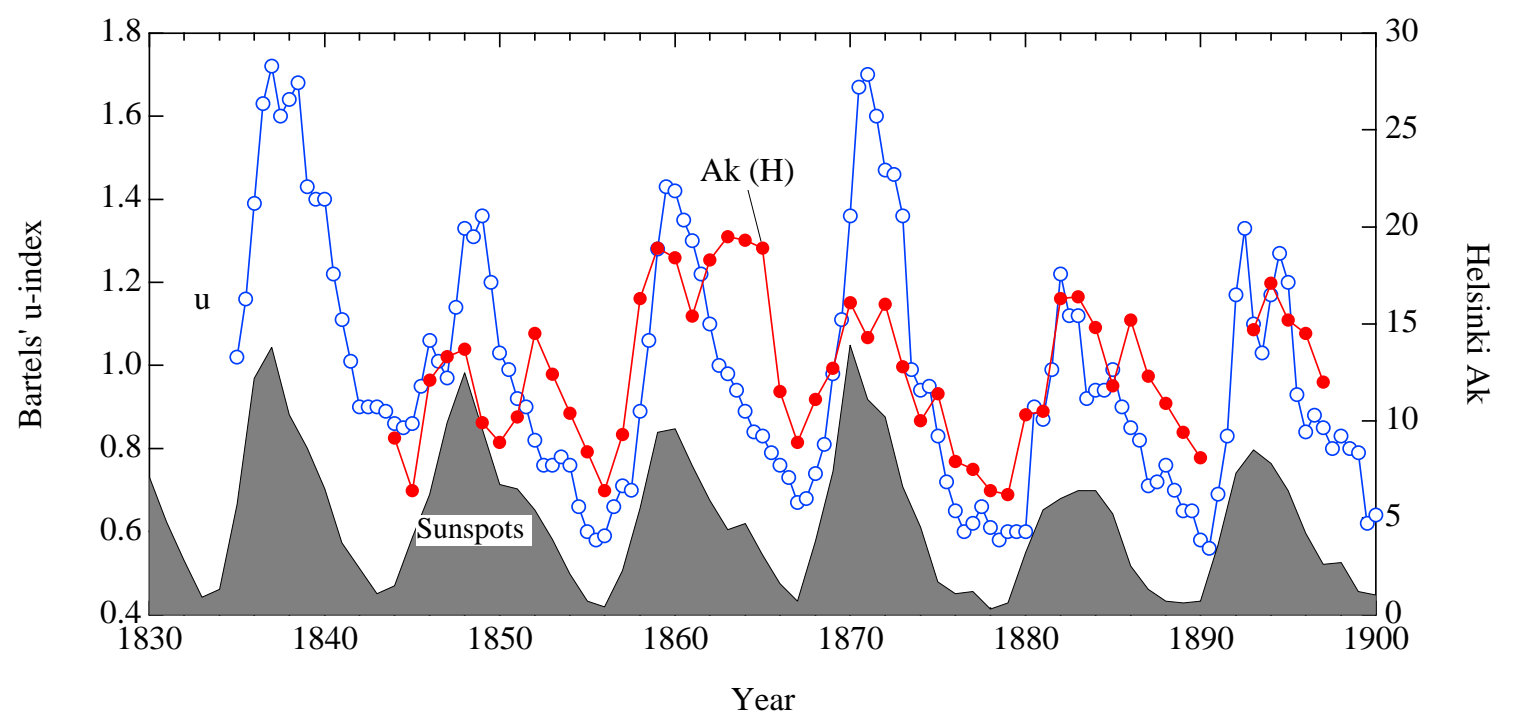

Fig. 6. Annual means of Helsinki $A k(H)$ and Bartels' mid-latitude activity index $u$. Sunspot numbers are shown at the bottom.

The medium-range part of the spectrum from about one year to three years contains a rich concentration of spectral lines. Kane (1997) found quasi-biennal and quasi-triennal oscillations in the $a a$-series, 1868-1994. Their counterparts in the present $a a$-spectrum are 1.5-year, 1.9-year and 2.8year peaks (Fig. 4). The Helsinki $A k(D)$-data reproduces these lines at 1.5 years, 2.1 years and 3.5 years, but in the $H$ data there appears a single merged line peaked at 2.5-years, in addition to the 1.5-years peak. However, the distribution of the lines and their amplitudes depend on selected time intervals in the FFT. According to Kane (1997) and Mursula et al. (2003), quasi-biennal and quasi-triennal oscillations do not appear similarly in every sunspot cycle, since their period amplitude varies from one sunspot cycle to another.

The annual line $(365.25 \mathrm{~d})$ is present in both $A k(H)$ and $A k(D)$ spectra but, similar to the result by Delouis and Mayaud (1975), only very weakly in the $a a$-series. The anti-podality of the two $a a$-stations decreases partly the amplitude of the annual line in the power spectrum but does not cancel it completely. The existence of the annual line in both the $A k(D)$ and $A k(H)$ series is probably a signature of an incomplete elimination of the $S r$-variation in the determination of the $K$-indices, and the strong annual variability of the $S r$ is present in the index series, especially in $A k(H)$. However, all annual variation cannot be explained by the $S r$-contamination. As shown, for example, by Mursula and Zieger (2001), the annual periodicity can often attain large values and has an opposite phase during successive solar minima. However, in a long $F F T$, as calculated here, these properties tend to decrease the overall annual power and thereby decrease the significance of this important periodicity. As explained in these papers, the reason for these specific properties is the solar north-south asymmetry, which can also be seen in solar wind properties.

The presence of an appreciable annual oscillation in the Helsinki data causes the spectral line splitting in the 27- d solar rotation (or Bartels' recurrence cycle) band, as demonstrated by Shapiro (1969) (see Fig. 4 ). We detected two lines: $25.0 \mathrm{~d}(=1 / \mathrm{f}+)$ and $29.1 \mathrm{~d}(=1 / \mathrm{f}-)$. The modulating period $(T)$ is, according to Shapiro (1969), $\mathrm{T}=2 /(\mathrm{f}+-\mathrm{f}-)=354.9 \mathrm{~d}$, which is reasonably close to the annual period. The wave which experiences the modulation has the period $2 /(\mathrm{f}++\mathrm{f}-)=26.9 \mathrm{~d}$ which is near to the solar-rotation period $27.3 \mathrm{~d}$ which is shown in the $a a$-series (27.2 d) in Fig. 4.

A permanent feature in the short-period part of the activity index spectrum is the appearance of the 13.5-d periodicity which is roughly half of the solar rotation period and thus apparently its second harmonic wave. Evidence of the existence of such periodicity has been obtained almost 100 years ago by Schuster (1905), who detected a periodicity of $13.6 \mathrm{~d}$. However, as pointed out, for example, by Clua de Gonzales et al. (1993) and Mursula and Zieger (1996, 1997), the 13.5$\mathrm{d}$ variation is related to the long-term predominance of the two-sector structure in the interplanetary magnetic field and the occurrence of two high-speed streams during one solar rotation.

The semiannual line is very sharp and the period is almost the same in all spectra: $182.0 \mathrm{~d}, 184.0 \mathrm{~d}, 182.6 \mathrm{~d}$ in $A k(H)$, $A k(D), a a$, respectively. The amplitude of the semiannual line in the $A k(D)$ spectrum is about one-third higher than the line in the $A k(H)$ spectrum. The ratio of the annual line is vice versa. The explanation to these differences is in the different seasonal variation of $D$ and $H$.

\subsection{Comparison with other index series}

\subsection{1 $R I$-index}

The 27-d recurrent tendency of the geomagnetic activity shown in the power spectra in Fig. 4 can be quantified by the autocorrelation method introduced by Sargent (1985). 


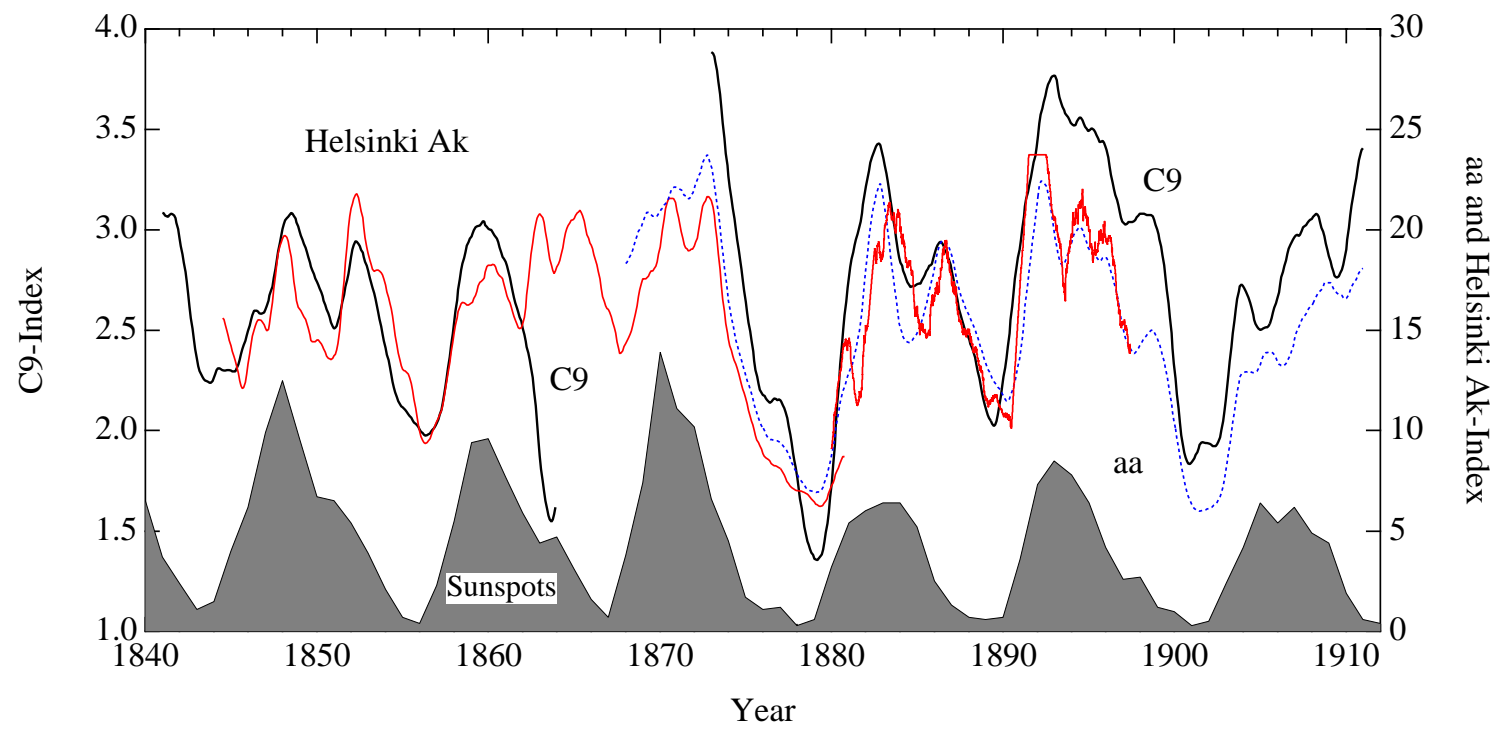

Fig. 7. Smoothed (365 d) daily values of Helsinki $A k(D), C 9$, and $a a$. The activity index $C 9$, representing the daily activity in a scale from 0 to 9 , is derived from magnetic observations at the Pavlovsk magnetic observatory (Zosemovich, 1981). Sunspot numbers are shown at the bottom.

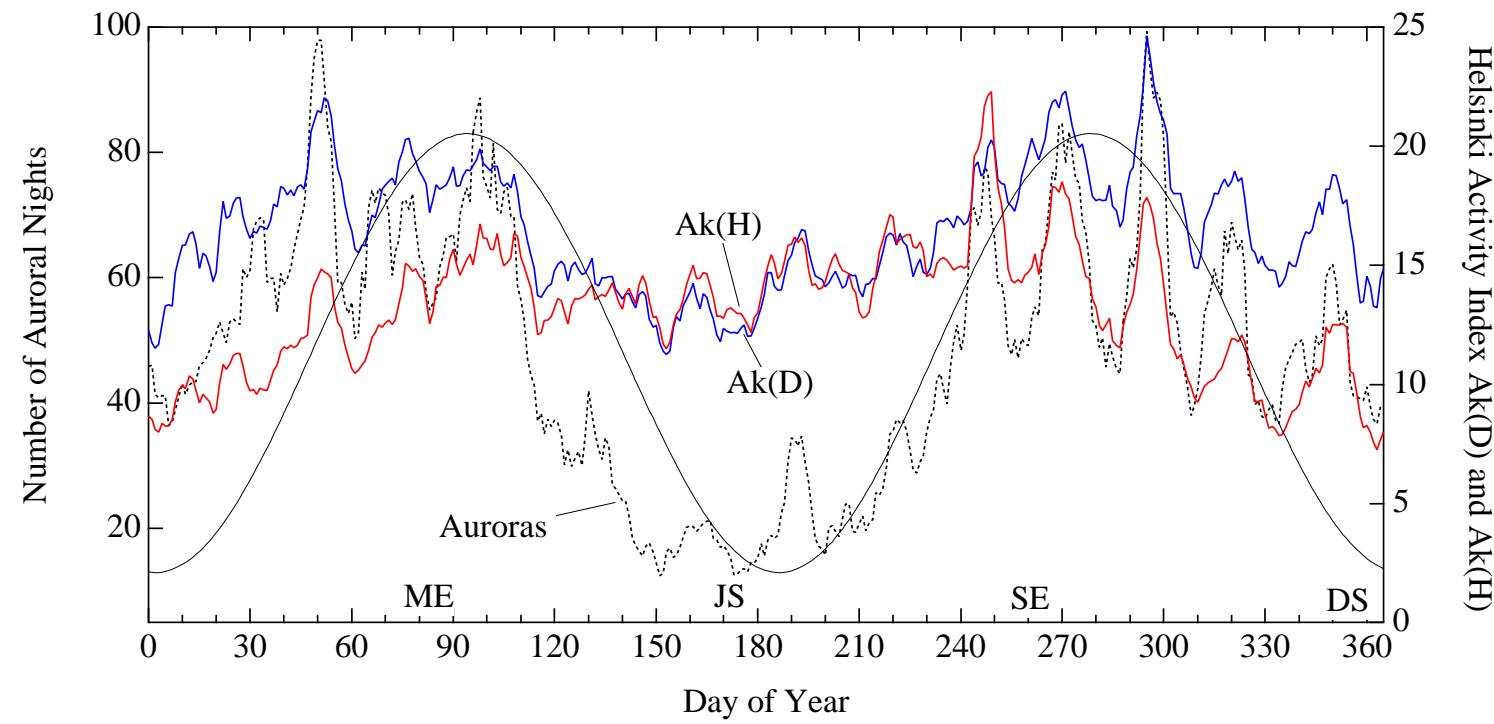

Fig. 8. Superposed epoch analysis of daily values of Helsinki $A k(D), A k(H), 1844-1880$, and of the occurrence of mid-latitude auroras. The auroral data are from Fritz's (1873) catalogue 1844-1872. The daily values are 7-d running means. The smooth curve shows the semiannual activity calculated from the Russell-McPherron model. ME = March equinox; JS = June solstice, $\mathrm{SE}=$ September equinox, DS = December solstice.

Figure 5 depicts the 27-d recurrent activity index $(R I)$ by Sargent (1985) for 1844-1900, as calculated from Helsinki data and from $a a$ since 1868 . As can be seen, the $R I$ index attains high values during the descending phase of the sunspot cycles during which the recurrent magnetic activity is prevalent. The behaviour of $R I$ is opposite during ascending phases of the solar cycles where, transient activity phenomena are dominant. The time patterns of the $R I$ s determined from the overlapping area of the two index series are very similar. The extension of the $R I$-series by Helsinki data is thus very plausible.

\subsection{2 $u$-index}

The $u$-index has been introduced by Bartels (1932). This index series starts in 1835 and continues until the 1930s. It is an early predecessor of the equatorial ring-current index Dst (e.g. Rangarajan, 1989) describing low-latitude magnetic activity. The $u$-index for $1835-1871$ is based on declination readings from two observatories and since 1872 on seven stations. Figure 6 shows a comparison between Bartels' $u$-index, Helsinki $A k$-values and sunspot numbers on the annual basis. One can see that the $u$-index follows closely 
increasing and decreasing sunspot numbers but it is insensitive to high geomagnetic activity (shown as peaks in the $A k$ curve) episodes associated with stable coronal hole structures during the descending phase of the sunspot cycle.

\subsubsection{C9-index}

The $C$ 9-index gives the magnetic activity level in a tenbinned scale; Rangarajan (1989). Daily values of $C$ 9-index have been derived by Zosemovich (1981) from the Pavlovsk observatory recordings for the years 1841-1864 and 18731979. This data set has been utilized by Zhang et al. (1989), who studied quasi-steady corotating structures of interplanetary magnetic disturbances during solar cycles 13-20. Figure 7 shows annual values of $C 9$, Helsinki $A k$, and $a a$ indices, as well as sunspot numbers. $C 9$ reveals the general features of highs and lows in geomagnetic activity similarly to the two other indices but it contains less fine structure.

\subsubsection{Auroral occurrence index}

It is a well-known fact that the occurrence of bright and rapidly moving auroral forms are associated with high levels of geomagnetic activity. Occurrence frequencies of magnetic activity and auroras are thus expected to be highly correlated. The famous auroral catalogue from Fritz (1873) contains the dates and times of visually observed auroras in Europe and in North America compiled from different data sources up to 1872. Figure 8 depicts a superposed epoch analysis of annual variation between 1844-1880 and shows for each day of year, the mean Helsinki $A k(H), A k(D)$, and auroral occurrence index (the number of auroral nights) derived from Fritz's book. The figure reveals the dominant semiannual wave with equinoctial maxima and solsticial minima in all indices. In addition, there are local maxima and minima approximately with a $27-d$ interval being remarkably synchronous with corresponding variations of auroral data. The occurrence of such repetitive peaks is rather unexpected and no explanation can be given as to why the peaks are separated by about $27 \mathrm{~d}$.

Note the enhanced local activity peak in mid-July near the June minimum, especially in the auroral data in Fig. 8. It represents the July activity phenomenon. As pointed out by several authors (e.g. Clua de Gonzales et al., 1993), great magnetic storms occur in July at least as often as during high activity seasons in March and September equinoxies, which is an unexplained phenomenon.

Usually the semiannual variation has been explained by the Russell-McPherron mechanism, in which the semiannual maxima correspond to the largest southward component of the interplanetary magnetic field occurring about two weeks after the astronomical equinox days (Russell and McPherron, 1973). However, recent works (e.g. Cliver et al., 2002; Svalgaard et al., 2002) are in favour of the equinoctial model, which, in comparison to the Russel-McPherron model, better predicts the dates of maxima and minima in the observed semiannual variation. In the superposed epoch analysis the unsmoothed activity index data $(A k(H)$ and $A k(D))$ have a cluster of almost equal activity peaks near the equinoctial and solsticial dates. Thus, it is difficult to decide which mechanism is driving the semiannual variation in the Helsinki data.

\section{Utilization of old historical geomagnetic observatory data}

The activity index series derived from the Helsinki data for 1844-1880 (Nevanlinna and Kataja, 1993), combined with the $a a$-series (1868-), have been utilized by many authors as proxy data for studies of long-term behaviour of solar activity (e.g. Mussino et al., 1994; Russell and Mulligan, 1995; Cliver and Boriakoff, 1996; Mursula and Zieger, 1997; Boteler et al., 1998. Rangarajan and Barreto, 2000; Mursula and Zieger, 2001; Mursula et al., 2003), studies on sunspot maximum predictions (Bounar et al., 1997; Kane, 1997; Wilson et al., 1998; Duhau and Chen, 2002; Duhau, 2003), and in solar flux studies, as well as in estimations of possible solar connections in the past and recent trends in the Earth's greenhouse effects (e.g. Wilson, 1998; Stamper et al., 1999; Lockwood et al., 1999; Pulkkinen et al., 2001; Lockwood, 2003). Alexandrescu et al. (1995) have utilized Helsinki secular variation data $(D)$ for studies on geomagnetic jerks.

We have also digitized hourly means from the Polar Year observatories Sodankylä (1882-1883) (Nevanlinna, 1999) and at Petsamo (1932-1933). Trials have been done to digitize hourly values of $D$ and $H$ from the $a a$-index observatory Greenwich published in the yearbooks. In the digital form are now the years 1842-1847. The quality is reasonably good in $D$, but in $H$ there seems to be problems in the base-line level.

An interesting analysis of old geomagnetic observations carried out by A. Celsius in Sweden has been published by Beckman (1999). He has studied the original magnetic observations made in March 1741 in Uppsala, when Celsius and his assistant D. Hiorter found, for the first time, that magnetic disturbances and auroras occur simultaneously. The hourly observations of declination reveal the typical daily $S r$-variation, which shows that more than 15000 observations by Celsius and Hiorter can be utilized in a meaningful way in studies of geomagnetic activity.

Systematic daily and hourly observations of declination have been made in several observatories in Europe since the 1780s. Part of this data has been compiled by Wolf (1884) for his studies on the change of the daily range of declination as a function of the variation of sunspot number 1781-1880. The original data utilized by Wolf exist in observatory yearbooks or similar publications and could be used for construction of long-term activity index series.

All digitized magnetic data from Finland can be found through the Internet: http://www.geo.fmi.fi/MAGN/magn and hourly values of $D$ from the WDC (Kyoto). 

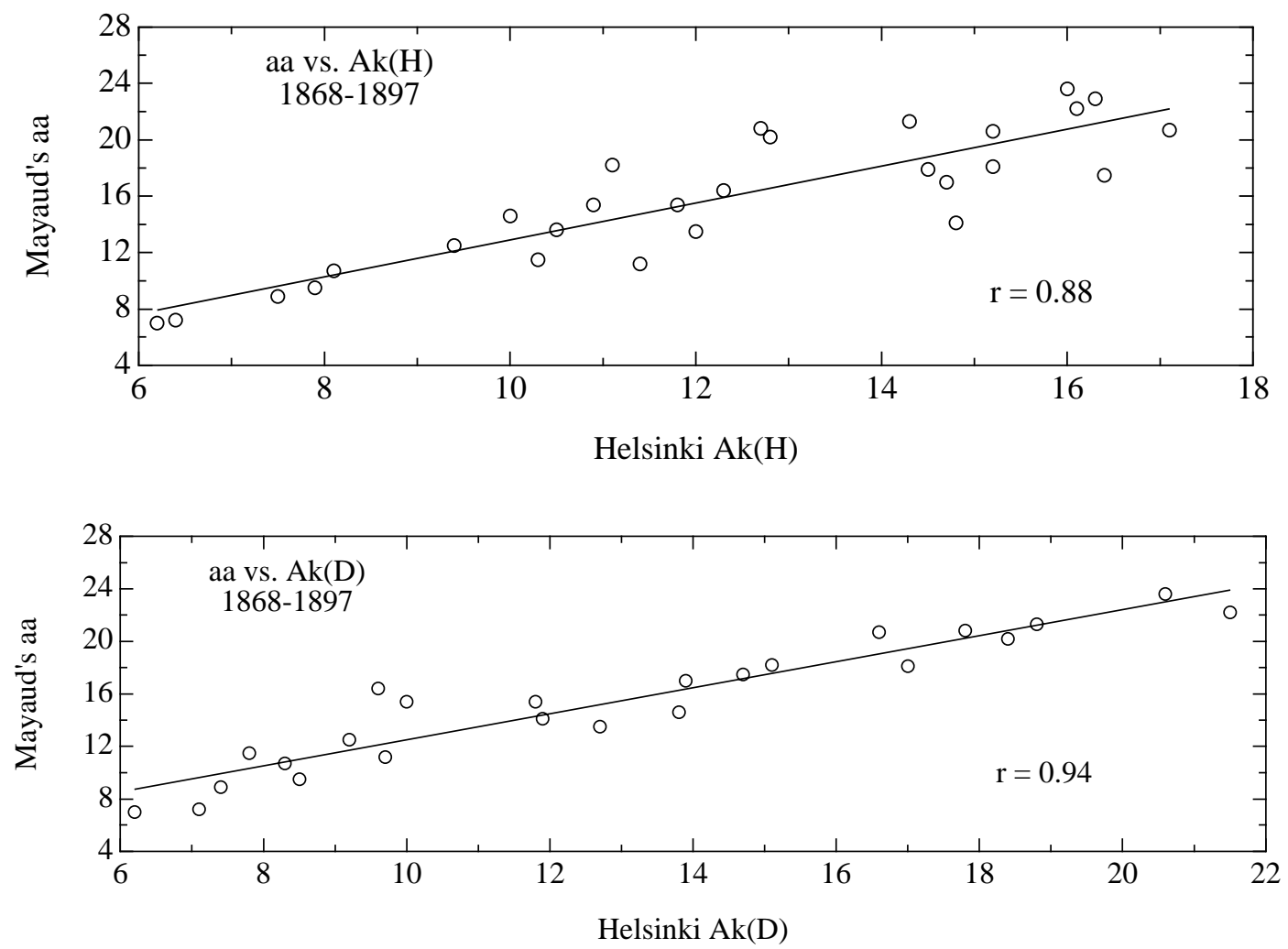

Fig. 9. Comparison between annual means of Mayaud's $a a$ and Helsinki activity indices $A k(H)$ (top) and $A k(D)$ (below). The Helsinkiindices overlap $a a$-index by 30 years from 1868 to 1897 . There are linear relationships between the indices: $a a=-0.2+1.31 A k(H)$ and $a a=2.5+0.99 A k(D)$ with correlation coefficients of 0.88 and 0.94 , respectively.

\section{Conclusions}

The Helsinki magnetic observatory was in operation for almost 70 years, 1844-1912. Magnetic recordings of declination $(D)$ and horizontal field $(H)$ have been made all the time at least once an hour, except for certain periods when the operations were temporarily stopped. Magnetic data that can be utilized exist for 1844-1909. Declination values have been converted into an absolute level, but $H$ refers to variation data only. There are about 2.0 million $H$ - and $D$ observations. Normal yearbook tables of $D$ have been published by Nevanlinna et al. (1992a, b) and Nevanlinna and Ketola $(1993,1994) . \quad B o t h ~ D$ - and $H$-data are available through Internet and WDC. The mean annual rate of secular change in 1844-1909 has been $0.12^{\circ}$ year, which is about twice as much as today in the Nurmijärvi magnetic observatory, the successor of the Helsinki observatory. The annual secular change at Helsinki during the first three decades of observations has been almost linear, with the mean rate of $+0.14^{\circ} /$ year (Fig. 1) until the mid 1870s. After a short transition time of a couple of years, the secular variation rate was slowed to a lower constant level of $+0.08^{\circ} /$ year. The transition phase is the earliest known jerk-phenomenon of the secular variation field (Alexandrescu et al., 1995).

Three-hour magnetic activity indices $(K)$ were computed from the hourly readings of $H$ and $D$ from 1844 through
1897. The algorithm applied was a slight modification of the so-called $F M I K$-index method approved by IAGA (Sucksdorff et al., 1991; Menvielle et al., 1995). The Helsinki Akseries give information from a time interval of 53 years covering almost five sunspot cycles (cycles 9-13). The homogenized magnetic activity series of $A k(D)$ made it possible to extend the longest acitivity series $a a$ (starting in 1868) by two solar cycles, 1844-1868 (Nevanlinna and Kataja, 1993). The correlation of monthly means of $A k$ (Helsinki) and $a a$ in the overlapping time interval is high, 0.96 ; thus, we can call the combined $A k-a a$ series as a pseudo $a a$, giving an almost 160 -year long activity index series for studies of long-term solar-terrestrial variations. Several authors have utilized this series in various studies (see Sect. 5). As shown in Fig. 9, the linear correlation between $a a$ and the Helsinki indices is very good for 30 years in the overlapping time interval between 1868-1897, which means that the Helsinki index series (monthly and annual means) can be used in analysis of geomagnetic activity, together with $a a$.

An spectral-analysis of the daily values of the activity indices $A k(H)$ and $A k(D)$ shows that the known periodicities (solar cycle, annual, semiannual, solar rotation, and half solar rotation) are well established in the index series, confirming that the spectral content of the Helsinki data is comparable with other long-term activity index series. 
Table 1. Annual means of geomagnetic activity indices $A k(D)$ and $A k(H), 1844-1897$ calculated from the Helsinki observatory data. The dates of major data gaps are given.

\begin{tabular}{|c|c|c|c|c|}
\hline Year & $\mathrm{Ak}(\mathrm{D})$ & $\mathrm{Ak}(\mathrm{H})$ & $\begin{array}{l}\text { Missing data } \\
\text { Ak(D) }\end{array}$ & $\begin{array}{l}\text { Missing data } \\
\mathrm{Ak}(\mathrm{H})\end{array}$ \\
\hline 1844 & 15.2 & 9.1 & 01 January-30 June & 01 January-30 June \\
\hline 1845 & 12.4 & 6.4 & & \\
\hline 1846 & 15.6 & 12.1 & & \\
\hline 1847 & 16.6 & 13.3 & & \\
\hline 1848 & 18.9 & 13.7 & & \\
\hline 1849 & 14.9 & 9.9 & & \\
\hline 1850 & 13.7 & 8.9 & & \\
\hline 1851 & 15.4 & 10.2 & & \\
\hline 1852 & 22.3 & 14.5 & 01 September-22 September & 02 September-13 October \\
\hline 1853 & 17.0 & 12.4 & & \\
\hline 1854 & 15.8 & 10.4 & & \\
\hline 1855 & 12.9 & 8.4 & & \\
\hline 1856 & 8.9 & 6.4 & 13 July-09 October & 13 July-09 October \\
\hline 1857 & 11.7 & 9.3 & & \\
\hline 1858 & 16.6 & 16.3 & & \\
\hline 1859 & 17.6 & 18.9 & & \\
\hline 1860 & 17.4 & 18.4 & & \\
\hline 1861 & 16.3 & 15.4 & & \\
\hline 1862 & 18.1 & 18.3 & & 12 January-23 January \\
\hline 1863 & 19.6 & 19.5 & & \\
\hline 1864 & 19.0 & 19.3 & & \\
\hline 1865 & 20.9 & 18.9 & & 01 October-08 November \\
\hline 1866 & 18.0 & 11.5 & & \\
\hline 1867 & 14.2 & 8.9 & & \\
\hline 1868 & 15.1 & 11.1 & & \\
\hline 1869 & 17.8 & 12.7 & & \\
\hline 1870 & 21.5 & 16.1 & 16 June-11 September & 16 June-11 September \\
\hline 1871 & 18.8 & 14.3 & & \\
\hline 1872 & 20.6 & 16.0 & & \\
\hline 1873 & 18.4 & 12.8 & & \\
\hline 1874 & 13.8 & 10.0 & 01 June-30 June & 21 September-31 December \\
\hline 1875 & 9.7 & 11.4 & & 01 January-28 February \\
\hline 1876 & 8.5 & 7.9 & & \\
\hline 1877 & 7.4 & 7.5 & & \\
\hline 1878 & 7.1 & 6.4 & & \\
\hline 1879 & 6.2 & 6.2 & & \\
\hline 1880 & 7.8 & 10.3 & 28 October-31 December & \\
\hline 1881 & - & 10.5 & 01 January-31 December & 01 September-31 December \\
\hline 1882 & - & 16.3 & 01 January-31 December & 01 August-31 December \\
\hline 1883 & 14.7 & 16.4 & 06 July, November-31 December & \\
\hline 1884 & 11.9 & 14.8 & 19 November-30 November & \\
\hline 1885 & 10.0 & 11.8 & & \\
\hline 1886 & - & 15.2 & & \\
\hline 1887 & 9.6 & 12.3 & & \\
\hline 1888 & 11.8 & 10.9 & & \\
\hline 1889 & 9.2 & 9.4 & 01 August-17 August & \\
\hline 1890 & 8.3 & 8.1 & & \\
\hline 1891 & - & - & 01 January-31 December & 01 January-31 December \\
\hline 1892 & - & - & 01 January-31 December & 01 January-31 December \\
\hline 1893 & 13.9 & 14.7 & & 02 July -31 July \\
\hline 1894 & 16.6 & 17.1 & & \\
\hline 1895 & 17.0 & 15.2 & 29 April-31 December & \\
\hline 1896 & - & 14.5 & 01 January-31 December & \\
\hline 1897 & 12.7 & 12.0 & 01 Jun-31 December & 01 June-31 December \\
\hline
\end{tabular}


In many countries there exist much published but unutilized magnetic observations that comprise valuable sources for studying magnetic activity or secular variation. A rather continuous (hourly or so) series of magnetic variation could be compiled from existing observatory data at least in $\mathrm{Eu}-$ rope, where systematic observations have been made since the 1780s. Interesting and scientifically relevant results from the Helsinki series are encouraging examples for a continuation of the rescue of old magnetic measurements.

Acknowledgements. Thanks are given to A. Ketola who has performed all the laborious basic data handlings and prepared the yearbook tables of the Helsinki $H$ - and $D$-observations. The following persons have taken part in converting the original handwritten observations to electronic form: I. Apiola, T. Kangas, J. Lemmetty, T. Pellinen, V. Pellinen, H. Pirjola, T. Siili, V. Tuomi (†), M. Veijalainen, and pupils of the Hankasalmi upper secondary school, which is gratefully acknowledged. Thanks are given to L. Svalgaard and R. Pirjola for their valuable comments on the manuscript.

Topical Editor M. Lester thanks two referees for their help in evaluating this paper.

\section{References}

Alexandrescu, M., Gibert, D., Hulot, G., LeMouël, J.-L., and Saracco, G.: Detection of geomagnetic jerks using wavelet analysis, Journ. Geophys. Res., 100, 12 557-12 572, 1995.

Alexandrescu, M., Courtillot, V., and LeMouël, J.-L.: Geomagnetic field direction in Paris since the mid-sixteenth century, Phys. Earth Planet. Inter., 98, 321-360, 1996.

Alexandrescu, M., Courtillot, V., and LeMouël, J.-L: Highresolution secular variation of the geomagnetic field in western europe over the last 4 centuries: Comparison and integration of historical data from Paris and London, Journ. Geophys. Res., 102, 20 245-20 258, 1997.

Bartels, J.: Terrestrial magnetic activity and its relation to solar phenomena, Journ. Geophys. Res., 37, 1-52, 1932.

Beckman, O.: Remarkable observations on a Graham magnetic needle in London and Uppsala in the eighteenth century Bull, Scient. Instr. Soc., 61, 15-17, 1999.

Boteler, D. H., Pirjola, R. J., and Nevanlinna, H.: The effects of geomagnetic disturbances on electrical systems at the earth's surface, Adv. Space Res., 22, 17-27, 1998.

Bounar, K. H., Cliver, E. W., and Boriakoff, V.: Prediction of the peak sunspot number of solar cycle 23, Solar Phys., 176, 211216, 1997.

Cawood, J.: Terrestrial magnetism and the development of international collaboration in the early nineteenth century, Ann. Sci., 34, 551-572, 1977.

Cawood, J.: The magnetic crusade: Science and politics in early victorian Britain, ISIS, 70, 493-518, 1979.

Chapman, S. and Bartels, J.: Geomagnetism, Vol. I and II., Oxford, Clarendon Press, 1940.

Clilverd, M. A., Clark, T. D. G., Rishbeth, H., and Ulich, T.: The causes of long-term change in the $a a$ index, Journ. Geophys. Res., 107, doi:10.1029/2001JA00051, 2002.

Cliver, E. W. and Boriakoff, V.: The 22-year cycle of geomagnetic and solar wind activity, Journ. Geophys. Res., 101, 27 09127 109, 1996.
Cliver, E. W., Boriakoff, V., and Bounar, K. H.: Geomagnetic activity and the solar wind during the Maunder minimum, Geophys. Res. Lett., 25, 897-900, 1998.

Cliver, E. W., Kamide, Y., and Ling, A. G.: The semiannual variation of geomagnetic activity: Phases and profiles for 130 years of $a a$ data, J. Atmos. Sol.-Terr. Phys., 64, 47-53, 2002.

Clua de Gonzales, A. L., Gonzales, W. D., Severino, L., Dutra, G., and Tsurutani, B. T.: Periodic variation in the geomagnetic activity: A study based on $A p$ index, Journ. Geophys. Res., 98, 9215-9232, 1993.

Delouis, H. and Mayaud, P. N.: Spectral analysis of the geomagnetic activity index $a a$ over a 103 -year period, Journ. Geophys. Res., 80, 4681-4688, 1975.

Duhau, S.: An early prediction of maximum sunspot number in solar cycle 24, Sol. Phys., 213, 203-212, 2003.

Duhau, S. and Chen, Ch. Y.: The sudden increase of solar and geomagnetic activity after 1923 as a manifestation of a non-linear solar dynamo, Geophys. Res. Lett., 13, doi:10.1029/2001GL013953, 2002.

Fraser-Smith, A. C.: Spectrum of the geomagnetic activity index Ap, Journ. Geophys. Res., 77, 4209-4220, 1972.

Friis-Christensen, E. and Lassen, K.: Length of the solar cycle: An indicator of solar activity closely associated with climate, Science, 254, 698-700, 1991.

Fritz, H.: Verzeichnis beobachteter Polarlichter, Gerold's Son, Wien, 255, 1873.

Good, G. A.: The study of geomagnetism in the late 19th century, EOS, 69, 218-229, 1988.

Holmberg, P.: The history of physics in Finland 1828-1918, Societas Scientarium Fennica, Helsinki, 267, 1992.

Kane, R. P.: A preliminary estimate of the size of the coming Solar Cycle 23, based on Ohl's precursor method, Geophys. Res. Lett., 24, 1899-1902, 1997.

Lockwood, M., Stamper, R., and Wild, M. N.: A doubling of the Sun's coronal magnetic field during the past 100 years, Nature, 399, 437-439, 1999.

Lockwood, M.: Twenty-three cycles of changing open solar magnetic flux. Journ. Geophys. Res., 108, doi:10.1029/2002JA009431, 2003.

Malin, S. R. C. and Barraclough, D. R.: Humboldt and the Earth's magnetic field, Q. J. R. astr. Soc., 32, 279-293, 1991.

McConnell, A.: Geomagnetic instruments before 1900, Harriet Wynter Ltd, London, 75, 1980.

Menvielle, M. and Berthelier, A.: The K-derived planetary indices: Description and availability, Rev. Geophys., 29, 413-432, 1991.

Menvielle, M., Papitashvili, N., Häkkinen, L., and Sucksdorff, C.: Computer production of $K$ indices: review and comparison of methods, Geophys. J. Int., 123, 866-886, 1995.

Multhauf, R. P. and Good, G.: A brief history of geomagnetism and a catalog of the collections of the National Museum of American History, Smith. Inst., Stud. Hist. and Technol., 48, Smithsonian Inst. Press, Washington, D. C., 1987.

Mursula, K. and Zieger, B.: The 13.5-day periodicity in the sun, solar wind, and geomagnetic activity: The last three solar cycles, Journ. Geophys. Res., 101, 27 077-27 090, 1996.

Mursula, K. and Zieger, B.: Solar excursion phases during the last 14 solar cycles, Geophys. Res. Lett., 25, 1837-1840, 1997.

Mursula, K. and Zieger, B.: Long-term north-south asymmetry in solar wind speed inferred from geomagnetic activity: A new type of century-scale solar oscillation?, Geophys. Res. Lett., 28, 9598, 2001. 
Mursula, K., Zieger, B., and Vilppola, J. H.: Mid-term quasiperiodicities in geomagnetic activity during the last 15 solar cycles: Connection to solar dynamo strength, Sol. Phys., 212, 201217, 2003.

Mussino, M., Borello-Filisetti, O., Storini, M., and Nevanlinna, H.: Long-term variations in the geomagnetic activity level, II. Ascending phases of sunspot cycles, Ann. Geophys., 51, 10651072, 1994.

Nervander, J. J.: Mèmoire sur un galvanométre a châssis cylindrique par lequel on obtient immédiatement et sans calcul le mesure de l'intensité du courant électrique qui produit la déviation de l'aiguille aimantée, Ann. de Chemie et Phys, Paris, $55,1833$.

Nervander, J. J.: Observations faites à l'observatoire Magnétique et Météorolique de Helsingfors 1844-1848, Vol. I-IV, Helsinki, 1850 .

Nevanlinna, H.: The geomagnetic field in Finland and nearby countries, J. Geophys., 46, 201-216, 1979.

Nevanlinna, H.: New geomagnetic activity index series published for 1844-1880, EOS, Transaction, American Geophysical Union, 76, 233-234, 1995.

Nevanlinna, H.: Gauss' H-Variometer at the Helsinki Magnetic Observatory (1844-1912), Journ. Geomagn. Geoelectr., 49, 12091216, 1997.

Nevanlinna, H.: Geomagnetic observations at Sodankylä during the first international polar year (1882-1883), Geophysica, 35 1522, 1999.

Nevanlinna, H., Ketola, A., and Kangas, T.: Magnetic results from Helsinki magneticmeteorological observatory, Part I: Declination 1844-1853, Finn. Met. Inst., Geophys. Publ., 27, 155, 1992a.

Nevanlinna, H., Ketola, A., Häkkinen, L., Viljanen, A., and Ivory, K.: Magnetic results from Helsinki magneticmeteorological observatory, Part II: Geomagnetic activity 1844-1856, Finn. Met. Inst., Geophys. Publ., 30, 65, 1992b.

Nevanlinna, H. and Kataja, E.: An extension of the geomagnetic activity index series $a$ a from two solar cycles (1844-1868), Geophys. Res. Lett., 20, 2703-2706, 1993.

Nevanlinna, H. and Ketola, A.: Magnetic results from Helsinki magneticmeteorological observatory, Part III: Declination 18541880, Geomagnetic activity 1844-1880, Finn. Met. Inst., Geophys. Publ., 33, 193, 1993.

Nevanlinna, H., Ketola, A., Häkkinen, L., Viljanen, A., and Ivory, K.: Geomagnetic activity during solar cycle 9 (1844-1856), Geophys. Res. Lett., 20, 743-746, 1993.

Nevanlinna, H. and Ketola, A.: Magnetic results from Helsinki magneticmeteorological observatory, Part IV: Declination 18801909, Summary of observations 1844-1909, Finn. Met. Inst., Geophys. Publ., 36, 143, 1994.

Pulkkinen, T. I., Nevanlinna, H., Pulkkinen, P. J., and Lockwood, M.: The sun-earth connection in time scales from years to decades and centuries, Space Sci. Rev., 95, 625-637, 2001.

Rangarajan, G. K.: Indices of geomagnetic activity, In: Geomagnetism, edited by Jacobs, J. A., Academic Press, 3, 323-384, 1989.

Rangarajan, G. K. and Iyemori, T.: Time variations of geomagnetic activity indices $K p$ and $A p$ : an update, Ann. Geophys., 15, 1271-1290, 1997.

Rangarajan, G. K. and Barreto, L. M.: Long term variability in solar wind velocity and IMF intensity and the relationship between solar wind parameters and geomagnetic activity, Earth, Planets and Space, 52, 121-130, 2000.

Russell, C. T. and McPherron, R. L.: Semiannual variation of geo- magnetic activity, Journ. Geophys. Res., 78, 92-108, 1973.

Russell, C. T. and Mulligan, T.: The 22-year variation of geomagnetic activity: Implications for the polar magnetic field of the Sun, Geophys. Res. Lett., 22, 3287-3288, 1995.

Sargent, H. H.: Recurrent geomagnetic activity: Evidence for longlived stability in solar wind structure, Journ. Geophys. Res., 90, 1425-1428, 1985.

Shapiro, R.: Semiannual variation of geomagnetic disturbance and its modulation of shorter period variations, Journ. Geophys. Res., 74, 2356-2367, 1969.

Schröder, W. and Wiederkehr, K.-H.: Geomagnetic research in the 19th century: A case study of the German contribution, J. Atmos. Sol.-Terr. Phys., 63, 1649-1660, 2001.

Schuster, A.: Sun-spots and magnetic storms, Monthly Not., R. Astr. Soc. London, 65, 186, 1905.

Silverman, S. M.: Low latitude auroras: the storm of 25 September 1909, J. Atmos. Terr. Phys., 57, 673-685, 1995.

Simojoki, H.: The history of geophysics in Finland 1828-1918, Societas Scientarium Fennica, Helsinki, 157, 1978.

Stamper, R., Lockwood, M., and Wild, M. N.: Solar causes of the long-term increase in geomagnetic activity, J. Geophys. Res., 104, 28 325-28 345, 1999.

Stern, D. P.: A millenium of geomagnetism, Rev. Geophys., 40, doi:10.1029/2000RG000097, 2002.

Sucksdorff, C., Pirjola, R., and Häkkinen, L.: Computer production of $K$-indices based on linear elimination, Geophys. Trans., 36, 333-345, 1991.

Svalgaard, L., Cliver, E. W., and Ling, A. G.: The semiannual variation of great magnetic storm, Geophys. Res. Lett., 29, doi:10.1029/2001GL014145, 2002.

Svalgaard, L., Cliver, E. W., and Le Sager, P.: IHV - A new geomagnetic index, Adv. Space Res., in press, 2004.

Tsurutani, B. T., Gonzales, W. D., Lakhna, G. S., and Alex, S.: The extreme magnetic storm of 1-2 September 1859, Journ. Geophys. Res, 108, doi:10.1029/2002JA009504, 2003.

Vennerström, S. and Friis-Christensen, E.: Long-term and solar cycle variation of the ring current, Journ. Geophys. Res., 101, 24 727-24 735, 1996.

Willis, D. M., Stevens, P. R., and Crothers, S. R.: Statistics of the largest geomagnetic storms per solar cycle (1844-1993), Ann. Geophys., 15, 719-728, 1997.

Wilson, R. M.: Evidence for solar-cycle forcing and secular variation in the armagh observatory temperature record (1844-1992), Journ. Geophys. Res., 103, 11 159-11 171, 1998.

Wilson, R. M. and Barreto, L. M.: Use of $K p$ index of geomagnetic activity in the forecast of solar activity, Earth, Planets and Space, 51, 363-372, 1999.

Wilson, R. M, Hathaway, D. H., and Reichmann, E. J.: An estimate for the size of cycle 23 based on near minimum conditions, J. Geophys. Res., 103, 6595-6603, 1998.

Wolf, R.: Einheitliche Deklination-Variationen, Astr. Mitt. Zürich, $61,1,1884$.

Yukoyama, Y. and Yukutake, T.: Sixty year variation in a time series of the geomagnetic Gauss coefficients between 1910 and 1983, J. Geomag. Geoelectr., 43, 563-584, 1991.

Zhang, G., Gao, Y. G., Feng, Z., and Xu, Y.: Quasi-steady corotating structure of interplanetary geomagnetic disturbances: A survey of solar cycles 13-20, Journ. Geophys. Res., 94, 1235-1244, 1989.

Zosemovich, I. D.: Geomagnetic activity and stability of solar corpuscular radiation (in Russian), Science Press, Moscow, USSR, $86,1981$. 